\title{
Making Decisions About Supplement Use
}

\author{
Ronald J. Maughan and Susan M. Shirreffs \\ St Andrews University \\ Alan Vernec \\ World Anti-Doping Agency (WADA)
}

\begin{abstract}
The use of dietary supplements is widespread among athletes in all sports and at all levels of competition, as it is in the general population. For the athlete training at the limits of what is sustainable, or for those seeking a shortcut to achieving their aims, supplements offer the prospect of bridging the gap between success and failure. Surveys show, however, that this is often not an informed choice and that the knowledge level among consumers is often low and that they are often influenced in their decisions by individuals with an equally inadequate understanding of the issues at stake. Supplement use may do more harm than good, unless it is based on a sound analysis of the evidence. Where a deficiency of an essential nutrient has been established by appropriate investigations, supplementation can provide a rapid and effective correction of the problem. Supplements can also provide a convenient and time-efficient solution to achieving the necessary intake of key nutrients such as protein and carbohydrate. Athletes contemplating the use of supplements should consider the potential for both positive and negative outcomes. Some ergogenic supplements may be of benefit to some athletes in some specific contexts, but many are less effective than is claimed. Some may be harmful to health of performance and some may contain agents prohibited by anti-doping regulations. Athletes should make informed choices that maximize the benefits while minimizing the risks.
\end{abstract}

Keywords: anti-doping, athlete, dietary supplement, nutrition

Athletes use dietary supplements in the hope or expectation of a beneficial effect, which, for the elite athlete, generally means a positive effect on competitive performance. Such an effect may be achieved directly, by a specific effect on performance in competition, or indirectly by better health or by enhancing the adaptation to training. An effect in competition may be achieved by acute ingestion of a supplement immediately before or during the event itself, or it may be achieved by ingestion of the substance over a period of days, weeks, or even months beforehand. It is clear from the preceding papers in this series, as well as from the extensive literature on the topic, that some individuals may experience performance benefits from the use of some supplements in wellcontrolled laboratory conditions. It is equally clear, though, that there is no supplement that will produce positive outcomes for all consumers in all situations, that there are many supplements for which the evidence is equivocal at best, and that there are also many supplements for which there is little or no evidence of efficacy in any context.

There are several key questions that any athlete should ask before embarking on a program of supplement use, though few have the necessary training and skills to do so. The first is an assessment of the evidence base relating to safety and the second is a similar analysis in relation to efficacy, but most athletes will place these in reverse order. Thirdly, and especially for the elite athlete, the potential for a positive doping test must be considered. Athletes should have a good reason for using a supplement, and this means

Maughan and Shirreffs are with the School of Medicine, St Andrews University, St Andrews, United Kingdom. Vernec is with the Dept. of Science and Medicine, World Anti-Doping Agency (WADA), Montreal, Quebec, Canada. Address author correspondence to Susan M. Shirreffs at s.shirreffs@st-andrews.ac.uk. that there should be evidence of likely health or performance benefits from its use. The evidence relating to performance should be relevant to their own sporting situation, preferably with data collected from athletes competing in the same sport at a similar standard. Health effects may be seen as supporting training and competition performance, but the potential for adverse effects in later life is also highly relevant, though they may not be immediately apparent. It is often the case, however, that the evidence base is limited. Data on elite athletes are particularly scarce, in part because of the potential disruption to training programs and an understandable reluctance to submit to invasive procedures.

Athletes and those who advise them must take responsibility for everything that the athlete consumes, but the World Anti-Doping Agency (WADA) regulations mean that the athlete remains strictly liable for the presence of any prohibited substance found in an antidoping specimen, regardless of advice from others. It is naïve to simply expect that commercially-available products are effective and safe, and there is a long history of adulteration and contamination of food (Wiley, 1907) and dietary supplements (Swann, 2016) to show otherwise. Even where the evidence shows that a benefit may accrue, this does not mean that every consumer will benefit.

\section{Potential Benefits of Supplement Use}

Potential benefits of supplement use for elite athletes include: (a) correction of a nutrient deficiency that may impair health or performance, (b) a specific effect related to training or competition, (c) reassurance as to adequacy of nutrient intake, and (d) financial gain by sponsor endorsement.

There is limited evidence that nutrient deficiencies are more or less common in athletes than in the general population, but it must 
be recognized that population estimates are of little relevance to the individual athlete, except perhaps in identifying areas of potential concern. Most nutritional surveys of athletes are based on either dietary recall or prospective records and these are often compared with reference nutrient intakes (RNIs). This has little value as the RNI is a population estimate, and, by definition, we would expect that most $(98 \%)$ members of any group would have a nutrient requirement that is less than the RNI. Deficiencies cannot be identified from estimates of intake, but should be determined by measuring appropriate biomarkers. Where this has been done, it can be seen that some nutrients may be of particular concern to athletes, including, perhaps, iron and Vitamin D. Where the status is shown to be low by assessment of an appropriate biomarker, supplementation with essential micronutrients may be warranted as an effective short-term measure while an appropriate long-term food-based solution is sought. In the case of vitamin D, athletes living at high latitudes may not be able to achieve an adequate status without resorting to supplements (Kryzwanski et al., 2016). Athletes who avoid animal-based foods may also have a requirement for supplementation with vitamin $\mathrm{B}_{12}$ and possibly with other micronutrients too.

Although dietary supplements may not be promoted for the prevention or treatment of illness, it is obvious that many consumers use them for this purpose (Garthe \& Maughan, 2018). Sport-specific reasons for supplement use include a belief that the stress of intense training/competition cannot be met by food alone, and that supplements can offer a specific advantage in either training or competition. Commercial products aimed at athletes include a wide range of supplements aimed at stimulating immune function, reducing oxidative stress, and maintaining general health (Rawson, Miles, \& Larson-Meyer, 2018). There is also an awareness among athletes that successful competitors are using supplements, and the use of supplements is often endorsed or encouraged by influential individuals in the athlete's circle, including coaches and training partners. There is some evidence-largely anecdotal, but supported by evidence from surveys - that the amount of supplement used by athletes often exceeds the recommended amount (Garthe \& Maughan, 2018). This "more is better" philosophy is encouraged by the belief that rivals are using even higher doses. Even elite athletes may not have access to professional advice that might counter some of these beliefs. Heikkinen et al. (2011) reported that only $27 \%$ of the 372 elite Finnish athletes they surveyed in 2009 had an opportunity to consult a sports nutrition professional. Even when these opportunities are available, not all athletes choose to make use of them, preferring instead to get their nutrition advice from sources that they may see as being more congenial.

A review of the evidence suggested that the beliefs that supplements can confer health and performance benefits may be erroneous and concluded that "with the possible exceptions of vitamin D and omega-3 fatty acids there is no data to support the widespread use of dietary supplements in Westernized populations; indeed, many of these supplements may be harmful" (Marik \& Flemmer, 2012, p. 159). Though the quality of the evidence on which these conclusions were based was often poor and the analysis of the evidence was perhaps not as rigorous as it might have been, this review does raise legitimate concerns regarding the widespread assumption that supplement use confers health benefits on the consumer and that it is free from any risk of adverse health outcomes. It is also the case that those who consume supplements may be least in need of them. Based on data from the US National Health and Nutrition Examination Survey, Rock (2007, p. 277S) concluded that "individuals who use dietary supplements generally report higher dietary nutrient intakes and healthier diets in studies in which dietary data were also collected." The challenge, therefore, is to ensure that these products are used by those who might benefit while limiting their use by athletes who will almost certainly not experience a benefit and who might experience negative outcomes. The use of a supplement even as simple as iron is not without some risk and iron overload can be a serious problem (Zoller \& Vogel, 2004).

For some-perhaps the majority - of the products on sale, it is impossible to find good evidence in the form of randomized, placebo-controlled intervention trials (Maughan et al., 2018). Supplement sales often rely instead on endorsements by successful athletes, who may or may not have used the product and whose success is likely the result of various other factors. Where evidence does exist, measurements are seldom made on elite athletes and it is very likely that the factors that limit performance may be different in the elite athlete than from those that limit performance in the untrained or recreationally active individuals who most often participate in laboratory studies. This may affect the response to supplementation. For example, several studies have shown that acute supplementation with nitrate can reduce the oxygen cost of exercise and enhance performance, as reviewed by Jones (2014), but this is by no means a universal finding (Betteridge et al., 2016; Kramer et al., 2016; Wylie et al., 2016). Some investigations have found no effect in well-trained subjects (Cermak et al., 2012; Wilkerson et al., 2012). Whether these discrepant findings result from differences in training status, exercise intensity and duration, supplementation protocol, or other factors remains as yet unclear in spite of extensive research on this topic in recent years, but this does highlight the need for care in the applications of laboratory findings to different sporting contexts (Jones, 2014).

The exercise models used in laboratory studies may or may not be relevant to the athlete's sport and may not even be real measurements of exercise performance. The "anaerobic threshold" in its various manifestations, for example, can be shown to correlate with endurance performance in a heterogeneous population, but may not be a good marker of performance in a more homogeneous population (Faude et al., 2009) and it can change in the opposite direction from performance changes in response to nutritional interventions. In spite of this, however, changes in this measure in response to a supplement intervention are sometimes used as evidence of a performance effect (Graef et al., 2009). Similarly, the Physical Working Capacity at Fatigue Threshold $(\mathrm{PWC}[\mathrm{FT}])$ is an indirect measure, based on electromyographic measurements made during an incremental test, that may or may not be relevant to exercise performance (DeVries et al., 2007). Nevertheless, studies using the PWC(FT) have concluded that a period of supplementation with Beta-alanine can improve muscle endurance (Stout et al., 2008), even though no measure of performance was made.

No serious attempt has been made to evaluate the efficacy of many of the supplements used by athletes, nor to evaluate the many of those supplements that are popular with the general population. This is at least in part due to the difficulties involved in assessing efficacy. Many supplements are targeted at elite athletes, or at least at those training seriously and competing at a high level, but these individuals are seldom willing to participate in laboratory trials because of the inevitable disruption to training and competition schedules. The relevance of tests carried out on recreational athletes to the elite performer is doubtful, as highlighted above in the case of nitrate supplements. It seems quite possible that the factors that limit performance differ in the truly elite athlete from those in the untrained or recreationally-active individual. 
There are also some real difficulties in assessing efficacy of supplements. Even something as simple as exercise performance cannot be measured without some degree of uncertainty due to the inherent variability in performance. The validity, reliability, and sensitivity of the tests that are commonly employed as a measure of exercise performance has generated considerable controversy in recent years. Constant power tests to volitional exhaustion have been employed to examine the influence of various interventions on performance, but this method of testing has been criticized for a lack of ecological validity and poor test-retest reliability. This view is supported by the findings of Jeukendrup et al. (1996), who found a large day-to-day variability (coefficient of variation [CV] 27\%) in time to exhaustion tests, and a much smaller variability in a time trial protocol $(<4 \%)$. Data from our research group report more consistent performance in a constant power to fatigue test (CV 6\%) when preexercise conditions are standardized and adequate familiarization with the test is given (Maughan et al., 1989). Recent reports have highlighted similar errors of measurement when changes in performance are normalized across tests (Hinckson \& Hopkins, 2005). A key factor to consider when selecting an appropriate exercise test is its sensitivity, and the smallest worthwhile effect that can be reliability detected. Amann et al. (2008) demonstrated that time to exhaustion and time trial protocols display a similar sensitivity to the effects of hypoxia and hyperoxia on performance, and suggest that this finding will extend to other factors influencing performance. This is brought about by larger effects on performance in response to an intervention with constant power tests than are typically observed in time trial protocols: this compensates for the larger test-retest variability, resulting in a very similar signal-to-noise ratio to that seen with time-trial protocols (Amann et al., 2008; Currell \& Jeukendrup, 2008). In some research situations, the obvious limitation of a time-trial-type test is difficulty in comparing the effect of an intervention on the physiological response to exercise, since power output fluctuates and at any given time one individual's relative power output may vary greatly from that of other participants.

It is essential that those who consider the use of supplements understand the limitations of the experimental evidence. The margin between first and second in an Olympic final is generally very small - as little as one thousandth of a second in a track cycling event lasting about $4 \mathrm{~min}$-and even the difference between first and last may be much smaller than the sensitivity of laboratory tests of performance. Showing that a supplement does not improve performance of a group of subjects in a laboratory test does not mean that it may not have worthwhile benefits for some athletes. This has led to increasing discussion of "responders" and "nonresponders" in populations of subjects who participate in any given study. This may be entirely appropriate in some situations. We know, for example, that iron-deficient individuals are likely to show improved performance in response to a period of iron supplementation, while no such improvement would be likely in those who are iron replete when supplementation is initiated: indeed, the risk of iron toxicity resulting from excessive intake in supplementary form is very real (Zoller \& Vogel, 2004). An example of inappropriate use of this approach is that of Hoffman et al. (2006), who examined the effect of a dietary supplement or placebo on various physiological parameters in 10 subjects. They reported that there were no significant differences, but that 7 of the 10 subjects were considered responders: perhaps unsurprisingly, statistical analysis of the data from these 7 subjects only showed significant differences between supplement and placebo. The authors concluded that "It appears that consuming a nutritionally-enriched coffee beverage may increase resting energy expenditure in individuals that are sensitive to the caffeine and herbal coffee supplement" (Hoffman et al., 2006, p. 35). Simply excluding those subjects who do not give the desired result will always - and completely inappropriately_give statistically significant results. To truly establish whether an individual can be identified as a responder or a nonresponder requires multiple tests to establish that the response is consistent. Where some subjects improve and some do not in a single exposure to the test conditions, the explanation may simply be random variation in response.

If something as simple as endurance performance cannot be measured reliably, the difficulties in assessing efficacy are magnified many times when there is a less well-defined endpoint. Even with a very large investment of time and money, it is unrealistic to expect clear evidence of efficacy in many of the areas that are important to athletes, such as wound healing, muscle soreness, immune function, and joint health. The Glucosamine/Chondroitin Arthritis Intervention Trial (GAIT) lasted 2 years and cost more than US\$12.5 million, but provided rather inconclusive results. Phase 1 of the study concluded that the dietary supplement combination of glucosamine plus chondroitin sulfate did not provide significant relief from osteoarthritis pain among all participants, although a small subgroup of study participants with moderate-to-severe pain showed significant relief with the combined supplements (Clegg et al., 2006). Phase 2 of the trial concluded that the supplements, either together or alone, appeared to fare no better than placebo in slowing loss of cartilage in osteoarthritis of the knee (Sawitzke et al., 2008). Supplement companies are understandably reluctant to make such large financial investments in research where the outcome is uncertain.

It is also important to consider not only the potential benefits of supplement use but also the costs and risks (Maughan et al., 2011). Some supplements are expensive and do not represent a good financial investment for the average athlete. Others may pose a risk to health or performance, while some may cause the athlete to fail a doping test. The issue of supplements and doping tests will be discussed in more detail later, but it is clearly difficult for the athlete to make an informed decision on supplement use as many of the issues at stake are unknown.

\section{Costs and Risks}

A number of potential negative effects associated with the use of dietary supplements have been identified. These include adverse analytical findings in doping tests, negative effects on performance, and adverse health effects. In addition, the high financial cost of many supplements should perhaps be noted. Athletes with limited financial resources may fail to properly prioritize their spending, including, ironically, skimping on good food choices.

Consumers are entitled to expect that supplements purchased are fit for purpose. It seems reasonable to expect that a supplement purchased in a retail outlet or via the internet will contain the ingredients listed on the label in the stated amounts and that it does not contain anything else. Although the majority of supplement companies probably do offer reliable products, there is some evidence that this may not always be the case (Maughan, 2005). There are some well-publicized examples of lack of adherence to good manufacturing practice and also some clear examples of fraudulent practices. It is difficult, though, to assess the extent of these problems, as there is no comprehensive testing program for dietary supplements. 
Two recent assessments of protein powders, which are generally considered to be low-risk products, illustrate some of the concerns. A 2010 review of 24 commercially-available protein supplements revealed lead contamination in two protein supplements; at the levels of contamination found, these products would deliver a daily dose of 6 to $18 \mu \mathrm{g}$ of lead (ConsumerLab $\left.{ }^{\circledR}, 2010\right)$. The cumulative effects of lead intake are potentially harmful. Even though the typical dose provided by these supplements may not be excessive when the recommended intake is consumed, it is recognized that many consumers far exceed the recommended amounts. In a similar analysis, ConsumerReports.org ${ }^{\circledR}$ (2012) reported results of analysis of 15 protein powders and drinks, which were purchased mainly in the New York metropolitan area or online, and were tested for the presence of arsenic, cadmium, lead, and mercury. Three products were found to contain levels of heavy metals in excess of the safe levels proposed by the US Pharmacopeia.

These problems are consistent with poor quality control in manufacturing and storage processes, and there is no other obvious explanation for the presence of these low-level contaminants. A more significant concern is raised by various reports of supplement contamination from the US Food and Drug Administration (FDA). The FDA website contains frequent reports of problems with supplements, with many of these reports relating to the presence in a wide range of supplement products of undeclared allergens, microbiological contamination, or foreign objects. Only rarely is action taken, and that action seldom amounts to more than a product recall. The extent of these recalls is apparent, however, from the FDA website, suggesting a rather widespread problem. Where relatively expensive ingredients are involved, some products are reported to contain little or no active ingredient but only inexpensive substitutes (Green et al., 2001). Harris et al. (2004) analyzed a commercial creatine product and showed that it contained little creatine; they confirmed this by showing that ingestion of this product was not followed by the expected rise in plasma creatine concentration. The substitute is sometimes difficult to identify, but some protein supplements have been shown to contain melamine, which had apparently been added as a low-cost substitute for the more expensive protein ingredients (Champagne \& Emmel, 2011).

\section{Sports Doping Resulting From Dietary Supplement Use}

A series of claims by athletes that positive doping outcomes-in particular, for the anabolic-androgenic steroid nandrolone-resulted from their use of dietary supplements led to an investigation commissioned by the Medical Commission of the International Olympic Committee. In an initial investigation, ingestion of supplements containing nandrolone precursors that were not declared on the label was found to result in the presence of the diagnostic metabolites for nandrolone in the urine of volunteers (Geyer et al., 2000). Even though the alarm was raised, athletes, and those responsible for their care, were slow to act on this information and positive doping tests continue to result from the use of dietary supplements that contain prohibited substances. Geyer et al. (2004) purchased a total of 634 nonhormonal nutritional supplements from 215 different suppliers in 13 different countries in 2000-2001. On analysis of these supplements, 11 different anabolic androgenic steroids, mainly prohormones of testosterone and nandrolone, were detected. Ninety-four samples $(14.8 \%)$ contained prohormones. No reliable data were obtained for 66 samples (10.4\%) because of matrix effects. Twenty-three samples contained prohormones of nandrolone and testosterone, 64 contained only prohormones of testosterone, and 7 contained only prohormones of nandrolone.

In a similar, more recent survey, an analysis of 58 supplements purchased through standard retail outlets in the United States found that $25 \%$ of the purchased products contained low levels of steroid contaminants and $11 \%$ were contaminated with stimulants (HFL, 2007). There are now many reports of the contamination of supplements with a wide range of agents that are prohibited by the antidoping regulations, including many that are potentially harmful to health (Ayotte et al., 2001; Catlin et al., 2000; Kamber et al., 2000), and more recent evidence shows that the problem continues (Mathews, 2018). In some cases, the amounts are small and variable, and it seems likely that accidental cross-contamination during manufacturing, processing, or packaging may be responsible. An analysis of the reasons for recalls of dietary supplements by the FDA reveals a clear pattern: anabolic androgenic steroids are most commonly found in muscle-building products, stimulants (such as ephedrine and amphetamine analogues) in tonic products, anorectic agents (such as sibutramine and fenfluramine) in weight loss products, and sildenafil and related compounds in sexual enhancement products. These undeclared pharmaceuticals can make what would otherwise be ineffective products into products that are effective in achieving their stated aims - this cannot simply be coincidence. According to Eichner and Tygart (2016), more than a thousand products have been identified to contain stimulants, anabolic-androgenic steroids, or pharmaceuticals. Many of these potent pharmaceuticals, however, have significant side effects; they may not only confer a high degree of efficacy on these products but also have adverse health effects, particularly with the excess doses sometimes used by athletes. Many, of course, are also prohibited by anti-doping regulations (World Anti-Doping Agency, 2017).

Small amounts of testosterone and of some other endogenous steroids may not result in a positive doping result, but ingestion of even very small amounts of some prohibited substances is likely to result in a positive test. In a study by Watson et al. (2009), 20 volunteers ingested $500 \mathrm{~mL}$ of water containing $5 \mathrm{~g}$ of creatine monohydrate (which was analyzed and shown to be free of steroids) to which $1.0,2.5$, or $5.0 \mu \mathrm{g}$ of 19-norandrostenedione had been added. Subsequent urine samples were collected and analyzed for 19-norandrosterone (19-NA), the diagnostic metabolite for nandrolone, which also results from the metabolism of 19-norandrostenedione. The threshold urinary concentration for detection of a doping infringement is $2.0 \mathrm{ng} / \mathrm{mL}$. Ingestion of the supplement resulted in mean peak urinary $19-\mathrm{NA}$ concentrations of $0.7,1.6$, and $3.9 \mathrm{ng} / \mathrm{mL}$ in the $1.0,2.5$, or $5.0 \mu \mathrm{g}$ trials, respectively. Under current WADA regulations, ingestion of the $1.0 \mu \mathrm{g}$ dose produced no positive doping tests, 5 subjects $(20 \%)$ tested positive in the $2.5 \mu \mathrm{g}$ trial, and 15 subjects $(75 \%)$ had urinary 19-NA concentrations exceeding $2 \mathrm{ng} /$ $\mathrm{mL}$ after ingesting $5.0 \mu \mathrm{g}$ of the steroid. These are vanishingly small amounts, with no effect on performance or health, but such levels could be the result of use at some time before the testing, so the rules are framed accordingly to maximize the chances of detecting illicit use. The consequence of a doping infraction to the reputation and career of an elite athlete should not be underestimated and should be carefully factored into the benefit/risk equation.

\section{Adverse Health Outcomes From Supplement Use}

Some supplements may actually cause harm to health, but adverse events can be difficult to identify, and products are usually 
withdrawn from the market only after a significant number of adverse events have occurred (Chatham Stephens et al., 2017). Haller and Benowitz (2000) identified a significant number of cardiovascular and central nervous system events associated with the use of dietary supplements containing ephedra alkaloids. In 2009, a range of products containing hydroxycitric acid was withdrawn from sale in the United States. According to the FDA, this action was based on 23 reports of serious health problems ranging from jaundice and elevated liver enzymes, to liver damage requiring liver transplant, and one death linked to liver damage (Food and Drug Administration, 2009). There are also case reports of pancreatitis in response to the ingestion of supplements containing hydroxycitric acid, sometimes labelled as Garcinia Cambogia (Melendez-Rosado et al., 2015; Grigos et al.,2016). In these cases, the adverse outcomes can be related to the known presence of harmful agents in the supplements. Where the presence of potentially toxic agents is not declared on the label, the likelihood of a link being established between supplement use and adverse outcomes is much more remote.

Nevertheless, numerous published case reports began to appear that linked supplement use to adverse health outcomes (Krishna et al., 2011; Krishnan et al., 2009). These were followed by case series, including data on adverse outcomes from use of herbal weight-loss supplements in Italy (Vitalone et al., 2011) and a report that described the development of hepatitis in a group of 20 Iranian male bodybuilders taking a cocktail of dietary supplements (Timcheh-Hariri et al., 2012). This in turn was followed by a review of patients attending eight United States referral centers that are part of the Drug-Induced Liver Injury Network (DILIN), from 2004-2013 (Navarro et al., 2014). This included all consecutive patients with liver injury referred to a DILIN center, and the final sample comprised $130(16 \%)$ of all subjects enrolled (839) who were judged to have experienced liver injury caused by herbal or dietary supplements (HDS). Of the sample, 45 had injury caused by bodybuilding HDS, 85 by non-bodybuilding HDS, and 709 by medications. Liver injury caused by HDS increased from $7 \%$ to $20 \%$ during the study period. More recently, nationally-representative surveillance data from 63 emergency departments were obtained by Geller et al. (2015) from 2004 through 2013 to describe visits to US emergency departments resulting from adverse events related to dietary supplements. They estimated that 23,005 emergency department visits per year were attributed to adverse events related to dietary supplements and that these visits resulted in an estimated 2,154 hospitalizations annually. Herbal or complementary nutritional products for weight loss and increased energy were commonly implicated.

Another source of information comes from analysis of samples of various supplements purchased at sales outlets. Weight-loss products seem to be particularly problematic, perhaps because of the size of the market and because of the easy availability of effective, though potentially harmful, pharmaceutical agents. Yoshida et al. (2015) analyzed a number of weight-loss products and identified the presence of sibutramine at pharmacological doses. This is a potent anorectic agent, and, as well as being included on the WADA Prohibited List, its sale has been discontinued in most countries because of adverse effects on the circulatory system. The FDA had earlier reported (FDA, 2010) that a single herbal weight loss product contained Fenfluramine, Propranolol, Sibutramine, and Ephedrine, yet none of these was included on the ingredient list on the product package and all are potentially harmful to health if used inappropriately. 2,4Dinitrophenol (DNP) is a powerful agent that acts by uncoupling the transmembrane mitochondrial proton gradient created by oxidative metabolism from the phosphorylation of adenosine diphosphate so that the energy of the proton gradient is lost as heat rather than being conserved. Soon after its discovery, the compound was used widely for weight loss but fell into disuse because of the serious side effects. As of 2011, at least 62 deaths resulting from the ingestion of DNP had been reported in the medical literature (Grundlingh et al., 2011). In spite of these concerns, Petróczi et al. (2015) found that DNP was present, albeit at low concentration $(<100 \mu \mathrm{g} / \mathrm{kg})$, in 14 out of 98 weight loss supplements that were analyzed. Problems continue to exist, as demonstrated by the presence in products marketed as dietary supplements of stimulants that are not approved for sale (Cohen et al., 2017).

Most reports have involved liver problems of varying degrees of severity, but tissues and organs other than the liver are affected. Li et al. (2015) reported the results of an epidemiological study to examine the relationship between the use of muscle-building supplements (MBSs) and testicular germ cell cancer (TGCC) risk. This was a population-based case-control study including 356 TGCC cases and 513 controls from the Eastern United States. The odds ratio (OR) for use of MBSs in relation to risk of TGCC was significantly elevated $(\mathrm{OR}=1.65,95 \%$ confidence interval [CI]: 1.11-2.46), and the associations were significantly stronger among early users, men with more types of MBSs used, and longer periods of use.

Even when adverse health outcomes of anabolic steroid use are well recognized by those who consume them, however, use of these agents continues in more than half of users (Melia et al., 1996). It is likely that similar responses will be observed with supplements, so education alone is unlikely to prevent the use of harmful supplements where a benefit is perceived by users. Many users seem to see potential benefits without recognizing the real risks.

\section{Quality Assurance Programs}

Various quality assurance programs for sports nutrition supplements are available. Unlike the testing carried out by the FDA, which is primarily concerned with consumer protection issues such as the presence of the active ingredients in the stated amounts and the absence of substances that may be harmful to health, the focus of these programs is on the testing of samples provided by manufacturers or distributors for the presence of WADA-prohibited substances. These sport-related programs are not complete quality assurance programs in that the presence of active ingredients is not usually verified.

Although athletes and those who are responsible for their care often see these programs as a guarantee of the integrity of products that have been tested, it is important to recognize that a limited panel of substances is tested for, and that the tests have limited sensitivity. In supplements tested through the Informed-Sport program in the United Kingdom, for example, the level of detection is set at $10 \mathrm{ng} / \mathrm{g}$ for steroids and $100 \mathrm{ng} / \mathrm{g}$ for stimulants (InformedSport, 2012). Some other schemes operate at different levels, and it is important to recognize this. For supplements that are consumed in large amounts, such as protein powders or drinks, a much more sensitive test is required than for supplements taken as small pills or capsules. If a protein powder contained $90 \mathrm{ng} / \mathrm{g}$ of a steroid such as nandrolone or one of its precursors, this would appear as a negative test if the limit of detection is set at $100 \mathrm{ng} / \mathrm{g}$. However, a $25 \mathrm{~g}$ portion of this product would deliver a dose of $2.3 \mu \mathrm{g}$ of the steroid and there is a good chance that this might result in a positive test for 
nandrolone if a sample was collected within a few hours of ingestion of the supplement (Watson et al., 2009, 2010). Even when a product batch is tested prior to release for sale, there may still be a risk, albeit a very low risk. De Hon and Coumans (2007) showed this by finding prohibited substances to be present in a random sample of products that had been subjected to a rigorous screening program.

Consumers must recognize that although supplement quality assurance schemes do offer considerable protection, these schemes are not an absolute guarantee of quality.

\section{Putting It All Together}

Some athletes may benefit from the use of some supplements and it is inappropriate and unrealistic to suggest that athletes should avoid supplement use. Vernec et al. (2013), however, suggested that before considering taking supplements, athletes should focus first on proper training, optimal recovery practices, and sound basic nutrition. If there is a true need for supplements, then they should follow some simple and practical guidance to minimize the risk:

- Do not rely on advice from friends, fellow athletes, or coaches but undergo a proper evaluation by a qualified physician and/ or sports nutrition professional familiar with sport and antidoping rules. It is quite likely that dietary supplements are not necessary and nutrient deficiencies may be corrected from food sources.

- Avoid any product making claims of performance enhancement or any exaggerated claims or uses of the words: stimulant, energy or muscle booster, enhancer, legal or alternate steroid, extreme, blast, weight loss. Even if no prohibited substance is listed on the label, the product may be spiked with one.

- Herbal stimulants and prohormones are especially high risk. Use of the terms herbal or natural does not in any way mean that the product does not contain a prohibited substance.

- Some companies offer guarantees of purity or are certified by other companies that do quality control. Verify the third-party testing system reputation and remember there are no absolute guarantees.

- Avoid any company that states their products are WADA approved. WADA or its accredited laboratories never test supplements or any products when not part of a doping control process. WADA cannot recommend any company or quality control system. In order to guarantee purity, each product batch would have to be tested for all prohibited substances.

- Avoid products containing multiple ingredients as there is a higher risk of contamination. Vitamins and minerals (often classified as supplements) should be from reputable pharmaceutical companies and should not be mixed with other products.

- Seek guidance from your anti-doping organization about recent information on contaminated or dangerous products in your part of the world (e.g., USA Anti-Doping Agency High Risk List).

It must be emphasized that these steps will not eliminate completely the risk of ingesting a prohibited substance, but will at least greatly reduce it. The various stages of the decision-making process are outlined in graphic form by Maughan et al. (2018).

\section{References}

Amann, M., Hopkins, W.G., \& Marcora, S.M. (2008). Similar sensitivity of time to exhaustion and time-trial time to changes in endurance. Medicine \& Science in Sports \& Exercise, 40, 574-578. PubMed doi:10.1249/MSS.0b013e31815e728f

Ayotte, C., Levesque, J.F., Cleroux, M., Lajeunesse, A., Goudreault, D., \& Fakirian, A. (2001). Sport nutritional supplements: Quality and doping controls. Canadian Journal of Applied Physiology, 26, S120-S129. PubMed doi:10.1139/h2001-047

Betteridge, S., Bescós, R., Martorell, M., Pons, A., Garnham, A.P., Stathis, C.C., \& McConell, G.K. (2016). No effect of acute beetroot juice ingestion on oxygen consumption, glucose kinetics, or skeletal muscle metabolism during submaximal exercise in males. Journal of Applied Physiology, 120(4), 391-398.

Catlin, D.H., Leder, B.Z., Ahrens, B., Starcevic, B., Hatton, C.K., Green, G.A., \& Finkelstein, J.S. (2000). Trace contamination of over-thecounter androstenedione and positive urine test results for a nandrolone metabolite. Journal of the American Medical Association, 284, 2618-2621. PubMed doi:10.1001/jama.284.20.2618

Cermak, N.M., Res, P., Stinkens, R., Lundberg, J.O., Gibala, M.J., \& van Loon, L.J. (2012). No improvement in endurance performance following a single dose of beetroot juice. International Journal of Sport Nutrition and Exercise Metabolism, 22, 470-478. doi:10.1123/ ijsnem.22.6.470

Champagne, A.B., \& Emmel, K.V. (2011). Rapid screening test for adulteration in raw materials of dietary supplements. Vibrational Spectroscopy, 55, 216-223. doi:10.1016/j.vibspec.2010.11.009

Chatham-Stephens, K., Taylor, E., Chang, A., Peterson, A., Daniel, J., Martin, C., ... Lewis, L. (2017). Hepatotoxicity associated with weight loss or sports dietary supplements, including OxyELITE Pro (TM) - United States, 2013. Drug Testing and Analysis, 9(1), 68-74. PubMed doi:10.1002/dta.2036

Clegg, D., Reda, D.J., Harris, C.L., Klein, M.A., O'Dell, J.R., Hooper, M.M., ... Williams, H.J. (2006). Glucosamine, chondroitin sulfate, and the two in combination for painful knee osteoarthritis. The New England Journal of Medicine, 354, 795-808. PubMed doi:10.1056/ NEJMoa052771

Cohen, P.A., Avula, B., Venhuis, B., Travis, J.C., Wang, Y.H., \& Khan, I.A. (2017). Pharmaceutical doses of the banned stimulant oxilofrine found in dietary supplements sold in the USA. Drug Testing and Analysis, 9(1), 135-142. PubMed doi:10.1002/dta.1976

ConsumerLab.com ${ }^{\circledR}$. (2010). Product review: Protein powders \& drinks (including sports, nutrition, and diet products). Retrieved from https://www.consumerlab.com/reviews/Nutrition_Powders_Shakes_ and_Drinks_Including_Protein_Diet_MealReplacement_and_Sports_ Endurance_Recovery_Products/NutritionDrinks/

ConsumerReports.org ${ }^{\circledR}$. Protein drinks. Retrieved from http://www. consumerreports.org/cro/2012/04/protein-drinks/index.htm

Currell, K., \& Jeukendrup, A.E. (2008). Validity, reliability and sensitivity of measures of sporting performance. Sports Medicine, 38, 297-316. doi:10.2165/00007256-200838040-00003

De Hon, O., \& Coumans, B. (2007). The continuing story of nutritional supplements and doping infractions. British Journal of Sports Medicine, 41, 800-805. PubMed doi:10.1136/bjsm.2007.037226

DeVries, H.A., Tichy, M.W., Housh, T.J., Smyth, K.D., Tichy, A.M., \& Housh, D.J. (2007). A method for estimating physical working capacity at the fatigue threshold (PWCFT). Ergonomics, 30(8), 1195-1204. doi:10.1080/00140138708966008

Eichner, A., \& Tygart, T. (2016). Adulterated dietary supplements threaten the health and sporting career of up-and-coming young athletes. Drug test. Analysis, 8, 304-306. 
Faude, O., Kindermann, W., \& Meyer, T. (2009). Lactate threshold concepts how valid are they? Sports Medicine, 39(6), 469-490. PubMed doi:10.2165/00007256-200939060-00003

Food and Drugs Administration. (2009). Warning on hydroxycut products. Retrieved from https://www.fda.gov/ForConsumers/Consumer Updates/ucm152152.htm

Food and Drugs Administration. (2010). FDA public health alert: Que She weight loss capsules contain potentially harmful ingredients. Retrieved from https://www.fda.gov/NewsEvents/Newsroom/Press Announcements/ucm 218427.htm

Garthe, I., \& Maughan, R.J. (2018). Athletes and supplements-prevalence and perspectives. International Journal of Sport Nutrition and Exercise Metabolism. 28(2). doi:10.1123/ijsnem.2017-0429

Geller, A.I., Shehab, N., Weidle, N.J., Lovegrove, M.C., Wolpert, B.J., Timbo, B.B., ... Budnitz, D.S. (2015). Emergency department visits for adverse events related to dietary supplements. The New England Journal of Medicine, 373, 1531-1540. PubMed doi:10.1056/ NEJMsa1504267

Geyer, H., Mareck-Engelke, U., Reinhart, U., Thevis, M., \& Schanzer, W. (2000). Positive doping cases with norandrosterone after application of contaminated nutritional supplements. Deutsche Zeitschrift fur Sportmedizin, 51, 378.

Geyer, H., Parr, M.K., Mareck, U., \& Schanzer, W. (2004). Analysis of non-hormonal nutritional supplements for anabolic-androgenic steroids - Results of an international study. International Journal of Sports Medicine, 25, 124-129. doi:10.1055/s-2004-819955

Graef, J.L., Smith, A.E., Kendall, K.L., Fukuda, D.H., Moon, J.R., Beck, T.W., ... Stout, J.R. (2009). The effects of four weeks of creatine supplementation and high-intensity interval training on cardiorespiratory fitness: A randomized controlled trial. Journal of the International Society of Sports Nutrition, 6, 18. PubMed doi:10.1186/1550-2783-6-18

Green, G.A., Catlin, D.H., \& Starcevic, B. (2001). Analysis of over-thecounter dietary supplements. Clinical Journal of Sports Medicine, 11, 254-259. doi:10.1097/00042752-200110000-00008

Grigos, A., Benmoussa, J., Sandhu, J., Chaucer, B., Clarke, M., \& Patel, S.H. (2016). Acute Pancreatitis Secondary to Garcinia Cambogia; The Unknown Cost of Herbal Supplements. Journal of the Pancreas, 17(3), 316-317.

Grundlingh, J., Dargan, P.I., El-Zanfaly, M., \& Wood, D.M. (2011). 2,4Dinitrophenol (DNP): A weight loss agent with significant acute toxicity and risk of death. Journal of Medical Toxicology, 7, 205-212.

Haller, C.A., \& Benowitz, N.L. (2000). Adverse cardiovascular and central nervous system events associated with dietary supplements containing ephedra alkaloids. The New England Journal of Medicine, 343, 1833-1838. doi:10.1056/NEJM200012213432502

Harris, R.C., Almada, A.L., Harris, D.B., Dunnett, M., \& Hespel, P. (2004). The creatine content of Creatine Serum ${ }^{\mathrm{TM}}$ and the change in the plasma concentration with ingestion of a single dose. Journal of Sports Sciences, 22(9), 851-857. PubMed doi:10.1080/02640410 310001658739

Heikkinen, A., Alaranta, A., Helenius, I., \& Vasankari, T. (2011). Dietary supplementation habits and perceptions of supplement use among elite Finnish athletes. International Journal of Sport Nutrition and Exercise Metabolism, 21, 271-279. doi:10.1123/ijsnem.21.4.271

HFL. (2007). Supplements and banned substance contamination: Offering and informed choice. Retrieved from http://www. informed-sport.com/sites/default/files/pdf/Supplements-BannedSubstance-Contamination.pdf

Hinckson, E.A., \& Hopkins, W.G. (2005). Reliability of time to exhaustion analyzed with critical-power and log-log modelling. Medicine \& Science in Sports \& Exercise, 37, 696-701. doi:10.1249/01.MSS. 0000159023.06934 .53
Hoffman, J.R., Kang, J., Ratamess, N.A., Jennings, P.F., Mangine, G., \& Faigenbaum, A.D. (2006). Thermogenic effect from nutritionally enriched coffee consumption. Journal of the International Society of Sports Nutrition, 3(1), 35-43. doi:10.1186/1550-2783-3-1-35

Informed-Sport. What detection levels should supplements be tested at? Retrieved from http://www.informed-sport.com/faq\#

Jeukendrup, A., Saris, W.H., Brouns, F., \& Kester, A.D. (1996). A new validated endurance performance test. Medicine \& Science in Sports \& Exercise, 28, 266-270. PubMed doi:10.1097/00005768199602000-00017

Jones, A.M. (2014). Influence of dietary nitrate on the physiological determinants of exercise performance: A critical review. Applied Physiology, Nutrition, and Metabolism, 39(9), 1019-1028. PubMed doi:10.1139/apnm-2014-0036

Kamber, M., Baume, N., Saugy, M., \& Rivier, L. (2000). Nutritional supplements as a source for positive doping cases? International Journal of Sport Nutrition and Exercise Metabolism, 11, 258-263. doi:10.1123/ijsnem.11.2.258

Kramer, S.J., Baur, D.A., Spicer, M.T., Vukovich, M.D., \& Ormsbee, M.J. (2016). The effect of six days of dietary nitrate supplementation on performance in trained CrossFit athletes. Journal of the International Society of Sports Nutrition, 13, Article Number: 39.

Krishna, Y.R., Mittal, V., Grewal, P., Fiel, M.I., \& Schiano, T. (2011). Acute liver failure caused by 'fat burners' and dietary supplements: A case report and literature review. Canadian Journal of Gastroenterology \& Hepatology, 25(3), 157-160.

Krishnan, P.V., Feng, Z.-Z., \& Gordon, S.C. (2009). Prolonged intrahepatic cholestasis and renal failure secondary to anabolic androgenic steroid-enriched dietary supplements. Journal of Clinical Gastroenterology, 43(7), 672-675. doi:10.1097/MCG.0b013e318188be6d

Krzywanski, J., Mikulski, T., Krysztofiak, H., Mlynczak, M., Gaczynska, E., \& Ziemba, A. (2016). Seasonal vitamin D status in Polish elite athletes in relation to sun exposure and oral supplementation. PLoS ONE, 11(10), e0164395. PubMed doi:10.1371/journal.pone.0164395

Li, N., Hauser, R., Holford, T., Zhu, Y., Zhang, Y., Bassig, B.A., ... Zheng, T.(2015). Muscle-building supplement use and increased risk of testicular germ cell cancer in men from Connecticut and Massachusetts. British Journal of Cancer, 112, 1247-1250. PubMed doi: 10.1038/bjc.2015.26

Marik, P.E., \& Flemmer, M. (2012). Do dietary supplements have beneficial health effects in industrialized nations: What is the evidence? Journal of Parenteral and Enteral Nutrition, 36, 159-168. PubMed doi:10.1177/0148607111416485

Mathews, N.M. (2018). Prohibited contaminants in dietary supplements. Sports Health: A Multidisciplinary Approach, 10(1), 19-30.

Maughan, R.J. (2005). Contamination of dietary supplements and positive drugs tests in sport. Journal of Sports Sciences, 23, 883-889. PubMed doi:10.1080/02640410400023258

Maughan, R.J., Burke, LM, Dvorak, J, et al. (2018). Dietary supplements and the high-performance athlete. International Journal of Sport Nutrition and Exercise Metabolism. 28(2). doi:10.1123/ijsnem. 2018-0020

Maughan, R.J., Fenn, C.E., \& Leiper, J. (1989). Effects of fluid, electrolyte and substrate ingestion on endurance capacity. European Journal of Applied Physiology and Occupational Physiology, 58, 481-486. PubMed doi:10.1007/BF02330701

Maughan, R.J., Greenhaff, P.L., \& Hespel, P. (2011). Risks and rewards of dietary supplement use by athletes. Journal of Sports Sciences, 29, S57-S66. PubMed doi:10.1080/02640414.2011.587446

Melia, P., Pipe, A., \& Greenberg, L. (1996). The use of anabolicandrogenic steroids by Canadian students. Clinical Journal of Sport Medicine, 6, 9-14. doi:10.1097/00042752-199601000-00004 
Melendez-Rosado, J., Snipelisky, D., Matcha, G., \& Stancampiano, F. (2015). Acute hepatitis induced by pure garciniacambogia. Journal of Clinical Gastroenterology, 49, 449-450. PubMed doi:10.1097/MCG. 0000000000000303

Navarro, V.J., Barnhart, H., Bonkovsky, H.L., Davern, T., Fontana, R.J., Grant, L., ... Vuppalanchi, R. (2014). Liver injury from herbals and dietary supplements in the U.S. Drug-Induced Liver Injury Network. Hepatology, 60(4), 1399-1408. PubMed doi:10.1002/hep.27317

Petróczi, A., Ocampo, J.A., Shah, I., Jenkinson, C., New, R., James, R.A., .. Naughton, D.P. (2015). Russian roulette with unlicensed fatburner drug 2, 4-dinitrophenol (DNP): Evidence from a multidisciplinary study of the internet, bodybuilding supplements and DNP users. Substance Abuse Treatment, Prevention, and Policy, 10, 39. doi:10.1186/s13011-015-0034-1

Rawson, E.S., Miles, M.P., \& Larson-Meyer, D.E. (2018). Dietary supplements for health, adaptation, and recovery in atheltes. International Journal of Sport Nutrition and Exercise Metabolism. 28(2). doi: 10.1123/ijsnem.2017-0340

Rock, C.L. (2007). Multivitamin-multimineral supplements: Who uses them? The American Journal of Clinical Nutrition, 85(1), 277S-279S. PubMed

Sawitzke, A.D., Shi, H., Finco, M.F., Dunlop, D.D., Bingham, C.O., 3rd, \& Harris, C.L. (2008). The effect of glucosamine and/or chondroitin sulfate on the progression of knee osteoarthritis: A report from the glucosamine/chondroitin arthritis intervention trial. Arthritis \& Rheumatism, 58, 3183-3191. doi:10.1002/art.23973

Stout, J.R., Graves, B.S., Smith, A., Hartman, M.J., Cramer, J.T., Beck, T.W., \& Harris, R.C. (2008). The effect of beta-alanine supplementation on neuromuscular fatigue in elderly (55-92 Years): A doubleblind randomized study. Journal of the International Society of Sports Nutrition, 5, 21. PubMed doi:10.1186/1550-2783-5-21

Swann, J.P. (2016). The history of efforts to regulate dietary supplements in the USA. Drug test. Analysis, 8, 271-282.

Timcheh-Hariri, A., Balali-Mood, M., Aryan, E., Sadeghi, M., \& Zanjani, B.R. (2012). Toxic hepatitis in a group of 20 male body-builders taking dietary supplements. Food and Chemical Toxicology, 50, 3826-3832. PubMed doi:10.1016/j.fct.2012.07.006

Vernec, A., Stear, S.J., Burke, L.M., \& Castell, L.M. (2013). A-Z of nutritional supplements: Dietary supplements, sports nutrition foods and ergogenic aids for health and performance: Part 48. British
Journal of Sports Medicine, 47(15), 998-1000. doi:10.1136/ bjsports-2013-092941

Vitalone, A., Menniti-Ippolito, F., Moro, P.A., Firenzuoli, F., Raschetti, R., \& Mazzanti, G. (2011). Suspected adverse reactions associated with herbal products used for weight loss: A case series reported to the Italian National Institute of Health. European Journal of Clinical Pharmacology, 67(3), 215-224. doi:10.1007/s00228-0100981-4

Watson, P., Houghton, E., Grace, P.B., Judkins, C., Dunster, P.M., \& Maughan, R.J. (2010). The effect of delivery mode on excretion patterns of nandrolone metabolites after ingestion of a nandrolone pro-hormone. Medicine \& Science in Sports \& Exercise, 42, 754-761. PubMed doi:10.1249/MSS.0b013e3181bf94d6

Watson, P., Judkins, C., Houghton, E., Russell, C., \& Maughan, R.J. (2009). Supplement contamination: Detection of nandrolone metabolites in urine after administration of small doses of a nandrolone precursor. Medicine \& Science in Sports \& Exercise, 41, 766-772. PubMed doi:10.1249/MSS.0b013e31818edaeb

Wiley, H.W. (1907). Foods and their adulteration. Philadelphia, PA: Blakiston.

Wilkerson, D.P., Hayward, G.M., Bailey, S.J., Vanhatalo, A., Blackwell, J.R., \& Jones, A.M. (2012). Influence of acute dietary nitrate supplementation on 50 mile time trial performance in well-trained cyclists. European Journal of Applied Physiology, 112(12), 4127-4134. doi:10.1007/s00421-012-2397-6

World Anti-Doping Agency. (2017). Prohibited list. Retrieved from https://www.wada-ama.org/en/what-we-do/prohibited-list

Wylie, L.J., Bailey, S.J., Kelly, J., Blackwell, J.R., Vanhatalo, A., \& Jones, A.M. (2016). Influence of beetroot juice supplementation on intermittent exercise performance. European Journal of Applied Physiology, 116(2), 415-425.

Yoshida, N., Numano, M., Nagasaka, Y., Ueda, K., Tsuboi, H., Tanimoto, T., \& Kimura, K. (2015). Study on health hazards through medicines purchased on the Internet: A cross-sectional investigation of the quality of anti-obesity medicines containing crude drugs as active ingredients. BMC Complementary and Alternative Medicine, 15, 430. PubMed doi:10.1186/s12906-015-0955-2

Zoller, H., \& Vogel, W. (2004). Iron supplementation in athletes - First do no harm. Nutrition, 20(7-8), 615-619. PubMed doi:10.1016/j.nut. 2004.04.006 